\title{
Molecular Mechanism of Crocin Induced Caspase Mediated MCF-7 Cell Death: In Vivo Toxicity Profiling and Ex Vivo Macrophage Activation
}

\author{
Hamid A Bakshi ${ }^{1 *}$, Faruck Lukmanul Hakkim², Smitha Sam ${ }^{3}$
}

\begin{abstract}
Background: Crocus sativus and its major constituent crocin are well established to have anti-cancer properties in breast cancer cells (MCF-7). However the role of $C$. sativus extract (CSE) and crocin on caspase signaling mediated MCF-7 cell death at molecular level is remains unclear. In this study, we tried to unravel role of CSE and crocin on caspase mediated MCF-7 cells death and their in vivo preclinical toxicity profiling and immune stimulatory effect. Materials and Methods: CSE extract was fractionated by HPLC and crocin was isolated and characterized by NMR, IR, and MS. MCF-7 cells were treated with both CSE and crocin and expression of Bcl-2 and Bax was assessed after 24 and 36 hours. Furthermore, caspase 3, caspase 8 and caspase 9 expression was determined by Western blotting after 24 hours of treatment. DNA fragmentation analysis was performed for genotoxicity of CSE and crocin in MCF-7 cells. The in vivo toxicity profile of CSE (300 mg/kg of b.wt) was investigated in normal Swiss albino mice. In addition, peritoneal macrophages were collected from crocin $(1,1.5$ and $2 \mathrm{mg} / \mathrm{kg}$ body weight) treated mice and analyzed for $e x$ vivo yeast phagocytosis. Results: Immunoblot analysis revealed that there was time dependent decline in anti-apoptotic Bcl-2 with simultaneous upregulation of Bax in CSE and crocin treated MCF-7 cells. Further CSE and crocin treatment downregulated caspase 8 and 9 and cleaved the caspase 3 after 24 hours. Both CSE and crocin elicited considerable DNA damage in MCF-7 cells at each concentration tested. In vivo toxicity profile by histological studies revealed no observable histopathologic differences in the liver, kidney, spleen, lungs and heart in CSE treated and untreated groups. Crocin treatment elicited significant dose and time dependent ex vivo yeast phagocytosis by peritoneal macrophages. Conclusions: Our study delineated involvement of pro-apoptotic and caspase mediated MCF-7 cell death by CSE and crocin at the molecular level accompanied with extensive DNA damage. Further we found that normal swiss albino mice can tolerate the maximum dose of CSE. Crocin enhanced $e x$ vivo macrophage yeast phagocytic ability.
\end{abstract}

Keywords: Crocus sativus - crocin - MCF-7 cells - Bcl-2 - caspase - DNA fragmentation - toxicity

Asian Pac J Cancer Prev, 17 (3), 1499-1506

\section{Introduction}

Breast cancer is the most common malignancy in women throughout the world, and it accounts for $18 \%$ of all female cancers and there are approximately 600,000 annual deaths worldwide (Kumar et al., 2011). Chemotherapy is the principal therapeutic option to treat cancer patients but emerging drug resistance, tumor relapse and post treatment toxicity limits their use in clinic and these hurdles facilitates breast cancer as number one killer in women (Carol et al., 2014). Finding a drug formulation to overcome above mentioned clinical consequences is an active area of cancer drug discovery research. In this context plants are promising sources for chemotherapeutic agents who can abate or reverse cancer development and/or progression. Number of studies suggests that many edible fruits, vegetables, herbs and spices contain chemicals that may reduce the incidence of cancer (Deng et al., 2002).

Crocus sativus L. commonly known as saffron is a dietary herb of the Iridaceae family. Principal components of saffron are safranal, crocin, picrocrocin and crocetin and they are pharmacologically active (Rios et al., 1996). Anticarcinogenic activity of saffron was reported in the beginning of 1990 and research on this subject has increasingly continued during the past decade (Salomi et al., 1991). Anti-cancer and anti-tumor properties of saffron have been studied in several cancer cell lines and animal model (Abdullaev, 2002; Abdullaev and EspinosaAguirre, 2004). It is well reported that saffron can induce apoptosis in different cancer cell lines (Tavakkol-Afshari et al., 2008; Mousavi et al., 2009a, 2009b).

${ }^{1}$ Department of Food Science and Human Nutrition, ${ }^{2}$ Biology Division, Department of Basic science, College of Applied science, A'Sharqiyah University, Ibra, Oman, ${ }^{3}$ Department of Research Jawaharlal Nehru Cancer hospital and Research Center, Bhopal *For correspondence: hamidbakshi@asu.edu.om, hamid.bakshi@gmail.com 
Our previous studies shown that saffron can inhibit the growth of different cancer cells such as breast (Bakshi et al., 2012), pancreatic (Bakshi et al., 2010), and lung (Bakshi et al., 2012) and it is also shown to be an active tumor remission agent in dalton lymphoma model (Bakshi et al., 2009). Crocin is major active component of saffron and it is reported by our group and elsewhere. It has been reported that crocin has different properties including antiplatelet (Liakopoulou-Kyriakides and Skubas, 1990), neuron-protecting (Abe and Saito, 2000), antiatherogenic (He et al., 2005), antioxidant (Chen et al., 2008), aphrodisiac (Hosseinzadeh et al., 2008), hypolipidemic effect by inhibiting pancreatic lipase, leading to the malabsorption of fat and cholesterol (Sheng et al., 2006), and anxiolytic-like effect in the rat (Pitsikas et al., 2008). Crocin possesses significant anti-proliferation effects on human colorectal cancer cells (Aung et al., 2007). This carotenoid can induce the significant alteration of gene expression profile of T24 (transitional cell carcinoma of bladder) cell. It is suggested that the antitumor effects of crocin are medicated at least in part by regulating the cell cycle controlling gene expression (Lv et al., 2008).

In the current study, we intended to elaborate the molecular mechanism of caspase mediated MCF-7 cell death induced by saffron. In vitro cytotoxicity of saffron on MCF-7 cells is well established by our group and others (Mousavi et al., 2008; Mousavi et al., 2011; Bakshi et al., 2012; Nikouei et al., 2013; Samarghandian and Borji, 2014). Further saffron reported for initiation of apoptosis in MCF-7 cells by flow cytometric analysis (Mousavi et al., 2009; Mousavi et al., 2011). However, the precise molecular mechanism of apoptosis induced by saffron and its active constituent crocin in MCF-7 cells is unclear. Flow cytometric analysis of apoptosis by propidium iodide staining does not indicate the exact mechanism of cell death rather it denotes the proportion of cells reached apoptotic state. Further In vivo preclinical toxicity profile and immunomodulatory effect of saffron is not yet reported. In order to get clear picture of caspase involvement in saffron medicated MCF-7 cell death in this study, we delineate efficacy of saffron on Caspase 3,8 and 9 at molecular level and DNA fragmentation as genotoxic marker. Further In vivo toxicity and macrophage activation of saffron were investigated in normal Swiss albino mice.

\section{Materials and Methods}

\section{Chemicals and reagents}

Roswell park memorial institute medium (RPMI) and fetal bovine serum (FBS; heat inactivated) was obtained from life technologies (GIBCO BRL), USA, gentamycin $(100 \mu \mathrm{g} / \mathrm{ml})$ and amphotericin B $(1 \mathrm{mg} / \mathrm{ml})$, were obtained locally. Penicillin/streptomycin 100units, Dimethyl sulfoxide (DMSO), Phosphate buffer saline (PBS), Sodium bicarbonate, Calcium chloride, HEPES Buffer, Sodium chloride and disodium hydrogen phosphate were purchased from Merck, USA. Polyclonal antibody to caspase 8 and monoclonal antibodies to caspases 3 and Bcl-2 were obtained from oncogene, USA and active caspase 9 antibodies, etoposide were obtained from Calbiochem, USA. All reagents were prepared using deionized (Millipore) distilled water. All other fine chemicals were obtained from Sigma, Mo, USA. All HPLC and analytical grade solvents and silica gel required for column purification and TLC were obtained from SISCO Research Laboratories, India. The precoated TLC plates mesh size 60-120 was obtained from E-MERCK India.

\section{Plant material and extraction}

Saffron stigma was powdered using mortar and pestle. Powdered materials were extracted with ethanol and it is store in $-20^{\circ} \mathrm{C}$ until use for experiment. The active component identified by HPLC (Figure 1).

Isolation and Characterization of Crocin from C. Sativus

Crocin was isolated from saffron as previously described method (Lussignoli et al., 1999). Briefly, $500 \mathrm{mg}$ saffron was washed thrice with $20 \mathrm{ml}$ ethyl ether, and the residual ether was evaporated in air. It was then suspended in $15 \mathrm{ml}$ of $30 \%$ methanol $(\mathrm{v} / \mathrm{v})$ in distilled water and stirred for 5 minutes at room temperature. The extract was filtered through a $0.45 \mu \mathrm{m}$ Millipore filter. It was then diluted with $10 \mathrm{mmol} / \mathrm{l}$ phosphate buffered saline (PBS, $\mathrm{pH}=7.4)$, and the concentration of crocin was adjusted to $25 \mu \mathrm{mol} / \mathrm{l}$, using the coefficient $€ 443=89,000 \mathrm{M}^{-1} \mathrm{~cm}^{-1}$ reported for crocin in aqueous solution (Jorgensen et al., 1997). The crocin structure (Figure 2) was elucidated on the basis of ${ }^{1} \mathrm{HNMR},{ }^{13} \mathrm{CNMR}$, IR, and mass spectral data.

\section{Drug preparation}

Different concentration of CSE $(25,50$ and $75 \mu \mathrm{g} / \mathrm{ml})$ was freshly prepared by reconstituting them in cell culture medium. Crocin $(1,1.5$ and $2 \mathrm{mg} / \mathrm{ml})$ was prepared in PBS.

\section{Cell lines and Culture Method}

MCF-7 cells were purchased from ATCC, USA. Cells were cultured in RPMI 1640 medium with $10 \%$ FBS and $1 \%$ antibiotics (Penicillin/streptomycin) and maintained in humidified cell incubator at $37^{\circ} \mathrm{C}$ and $5 \% \mathrm{CO}_{2}$.

\section{Western blot analysis}

The whole cell lysate was prepared from CSE (10 $\mu \mathrm{g} / \mathrm{ml})$ and crocin $(10 \mu \mathrm{g} / \mathrm{ml})$ treated MCF-7 cells after 24 and 36 hours as described earlier (Narayanan et al., 2000). Then whole cell lysate were resolved in a $10 \%$ SDS polyacrylamide gel electrophoretically and electro transferred onto a nitrocellulose membrane. The immunoblots were probed with Bcl-2, Bax and caspase 3 , 8,9 antibodies and were visualized with the NBT/BCIP chromogenic substrate and documented.

\section{DNA fragmentation by agarose gel electrophoresis}

Inter-nucleosomal cleavage of DNA was analyzed as described previously (Kim et al., 2001). Cells were seeded in 6-well plates at a concentration of $1 \times 10^{6}$ cells per $\mathrm{ml}$ of medium. Then cells were treated with CSE (25, 50 and $75 \mu \mathrm{g} / \mathrm{ml})$, Crocin $(25,50$ and $75 \mu \mathrm{g} / \mathrm{ml})$. Cells were harvested after 24 hours of treatment and DNA fragmentation was assessed by gel electrophoresis.

\section{Flow cytometric analysis}

MCF-7 cells were harvested after 24 hours of CSE 
Molecular Mechanism of Crocin Induced MCF-7 Cell Death: In Vivo Toxicity Profiling and Ex Vivo Macrophage Activation

and crocin treatment at $10 \mu \mathrm{g} / \mathrm{ml}$. DNA content analysis (Sub-G1) was done by flow cytometry using propidium iodide (PI, sigma) (Nicoletti et al., 1991). Flow cytometry was performed using a FACScan equipped with cell quest software (Becton Dickinson). The fluorescence emitted PI-DNA complex, was collected through an FL-2 Filter $(585 \mathrm{~nm})$.

\section{In Vito Toxicity Assessment}

Swiss albino (Mus muculus) male mice (25 - $30 \mathrm{~g}$ ) were maintained under standardized, environmental conditions $\left(22-28^{\circ} \mathrm{C}, 60-70 \%\right.$ relative humidity, 12 hours dark/light cycle and water ad libitum). Then animals were divided in to two groups $(n=16)$. Group I treated with vehicle (saline) and group II treated with CSE (300 mg/ $\mathrm{kg}$ of body weight) at weekly intervals of 60 days. All the experiments were conducted under the guidelines of Institutional Animal Ethical Committee.

\section{Histopathological analysis}

At the end of experimental period, animal were euthanized by cervical dislocation and liver, kidney, spleen, lung and heart tissues were dissected and tissue sections were stained with hematoxylin and eosin staining as described earlier (Landen et al., 2002). Microscopic evaluation was done blindly by pathologist.

Peritoneal macrophage activation in murine model by purified crocin

Animals were divided in to four groups $(n=4)$. Group I (control), group II (crocin; $1 \mathrm{mg} / \mathrm{kg}$ of body weight), group III (crocin; $1.5 \mathrm{mg} / \mathrm{kg}$ body weight) and group IV (crocin; $2 \mathrm{mg} / \mathrm{kg}$ of body weight).

Macrophage activation was analyzed as described earlier (Bajaj et.al 2001). Mice were orally treated with different doses of crocin regularly for five days. Then peritoneal macrophages were isolated from the treated and control mice. Then macrophage was incubated for 24 hours at $37^{\circ} \mathrm{C}$ in $5 \% \mathrm{CO}_{2}$. After harvesting, macrophage culture was co-incubated with heat inactivated yeast (Saacaromyes cereviceae) at $57^{\circ} \mathrm{C}$ for 45 minutes. Then macrophage cells with ingested yeast cell were counted. This was expressed as percentage of phagocytosis or

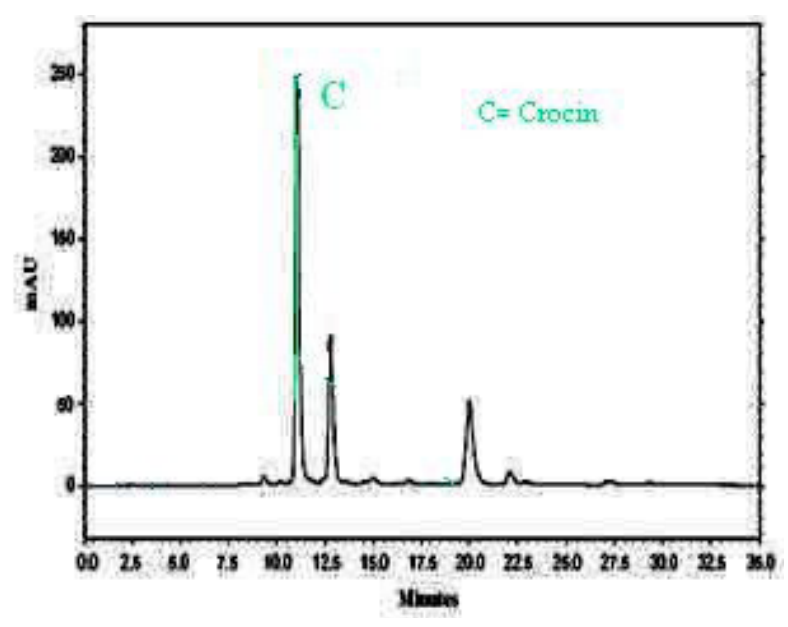

Figure 1. HPLC Profile of Crocin (Bakshi et al., 2010) percentage inhibition of yeast digestion which was calculated as

$\%$ inhibition of yeast digestion $=\frac{\text { No. of active macrophages } \mathrm{x} 100}{\text { Total no. of macrophages }}$

\section{Statistical evaluation}

Data presented as mean \pm SD of triplicates of three independent experiments. Experimental data were evaluated by students ' $t$ ' test and one or two way analysis of variance (ANOVA). Significant difference between each set of data were considered at the confidence level of $\mathrm{p}<0.05 \& \mathrm{p}<0.001$.

\section{Results}

Infrared (IR) spectrum of purified Crocin

IR spectra showed absorption bands at $945 \mathrm{~cm}^{-1}(-$ $\mathrm{CH}=\mathrm{CH}$-trans $), 1050 \mathrm{~cm}-1$ (-C-O-CO, ether), $1160 \mathrm{~cm}^{-1}$ (-C-O-ester), 1562 and $1618 \mathrm{~cm}^{-1}(-\mathrm{C}=\mathrm{C}-$, conjugated polyene), $2920\left(\mathrm{CH}_{3}\right.$-aliphatic) and $3420 \mathrm{~cm}^{-1}(-\mathrm{OH})$ (Table 1; Figure 3)

\section{Mass spectral analysis of purified crocin}

Purified crocin contained ions at M/Z 999, $\left[\mathrm{M}^{+} \mathrm{Na}\right]^{+}$, and 1015, $\left[\mathrm{M}^{+} \mathrm{K}\right]^{+}$(molecular mass 976) . Elimination of Terminal gentibiosyl groups was observed, generating peaks at $\mathrm{m} / \mathrm{z}$ 675, $\left[\left(\mathrm{M}^{+} \mathrm{Na}^{+} \mathrm{H}\right)^{-} \mathrm{Gnt}\right]$ and $691,\left[\left(\mathrm{M}^{+} \mathrm{K}-\mathrm{H}\right)^{-}\right.$ Gnt $]^{+}$(Figure 4)

\section{${ }^{1} \mathrm{H}$ and ${ }^{13} \mathrm{C}$ NMR Spectral analysis of purified crocin}

The ${ }^{1} \mathrm{H}$ and ${ }^{13} \mathrm{C}$ NMR spectra of compound showed simple sub duplet signals, because crocin has $\mathrm{C}_{2}$ structural symmetry. The ${ }^{1} \mathrm{HNMR}$ spectrum of crocin revealed a crocetin moiety $(\delta \mathrm{H}$ 6.49-7.31), anomoric doublets of $\beta$-configuration $(\delta \mathrm{H} 5.38 \mathrm{~d}, \mathrm{~J}=7.8 \mathrm{~Hz}), 4.55(\mathrm{~d}, \mathrm{~J}=6.9 \mathrm{~Hz})$, $4.13(\mathrm{~d}, \mathrm{~J}=7.8 \mathrm{~Hz}), 4.15(\mathrm{~d}, \mathrm{~J}=7.8 \mathrm{~Hz})$ and an anomeric

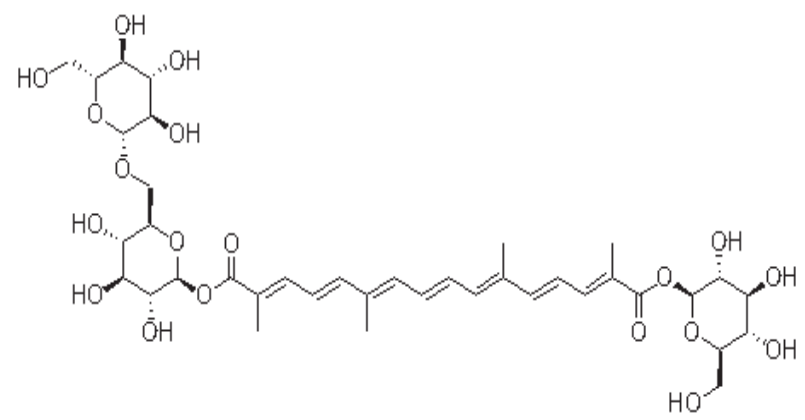

Figure 2. The Chemical Structure of Crocin (Bakshi et al., 2008)

Table 1. Infrared spectrum of Crocin

\begin{tabular}{lcc}
\hline S. No. & Wavelength $(\mathrm{cm}-1)$ & Functional group \\
\hline 1 & 945 & -CH=CH-trans \\
2 & 1050 & -C-O-CO, ether \\
3 & 1160 & -C-O-ester \\
4 & 1562 & -C=C- , conjugated polyene \\
5 & 1618 & -C=C- , conjugated polyene \\
6 & 2920 & CH3-aliphatic \\
7 & 3420 & -OH \\
\hline
\end{tabular}




\section{Hamid A Bakshi et al}

doublet of $\alpha$-configuration ( $\delta \mathrm{H} 5.06(\mathrm{~d}, \mathrm{~J}=3.6 \mathrm{~Hz})$. Two anomeric protons $(\delta \mathrm{H} 4.53,5.06)$ were shifted to a high magnetic field and two oxymethineo on $\mathrm{H}-2(\mathrm{\delta H} 4.39$ (dd, $\mathrm{J}=3.7,10.1 \mathrm{~Hz}), 4.83(\mathrm{~d}, \mathrm{~J}=6.9 \mathrm{~Hz})$ were shifted to a low magnetic field. This observation indicated the existence of a free hydroxyl group at an anomeric position on the glycosyl groups. Furthermore, HMBC correlations were observed between the $\mathrm{H} 2$ of the $\alpha$-glycoside and $\beta$-glycoside (Glucose C) at $\delta \mathrm{H} 5.06$ and $\delta \mathrm{H} 4.53$ and carbonyl carbons on the crocetin moiety at $\delta \mathrm{C} 167.92$ and $\delta C 167.11$ respectively. Based on this chemical and spectra data compound was determined to be an all transcrocetin $\beta$-D-2-deoxy glucopyranos-2-yl ester (Crocin).

$U$ p regulation of Bax and down regulation of $B c l-2$ by CSE and Crocin

To determine the mechanism of apoptotic induction in MCF-7 cells by CSE and crocin treatment, we analyzed the expression level of Bcl-2 and Bax by western blot. The immunoblot analysis showed gradual decline in the expression levels of Bcl-2 with marked increase in the Bax protein expression levels in a time dependent manner (Figure 5). Untreated MCF-7 cells showed basal expression levels of both proteins. This data suggest the involvement of Bcl-2 in the CSE and crocin induced apoptotic process.

\section{Role of CSE and crocin on DNA fragmentation}

To elucidate whether the CSE and crocin inhibits

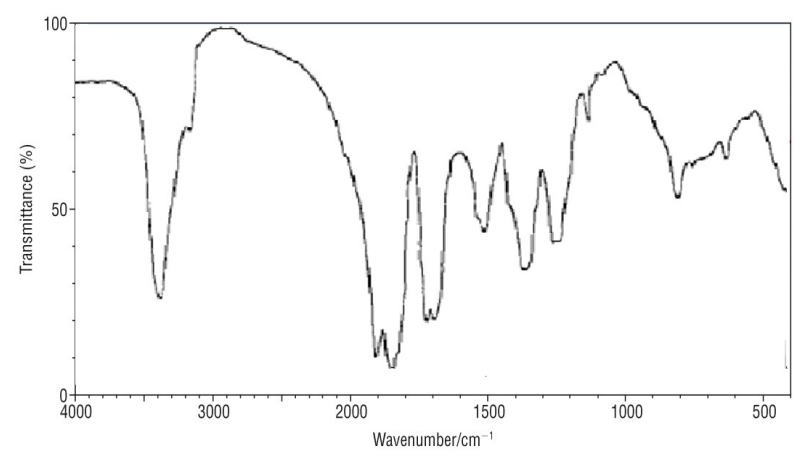

Figure 3. IR Spectrum of Crocin

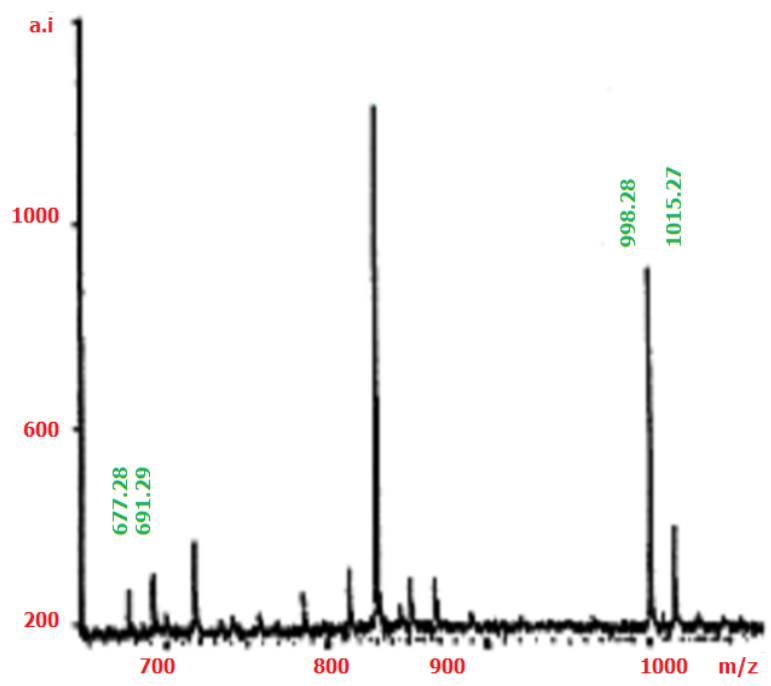

Figure 4. Mass Spectra of Crocin
MCF-7 cell proliferation through induction of apoptosis accompanied with irreparable DNA damage; we examined the cell death by DNA fragmentation. Each concentration of CSE and crocin exhibit significant DNA fragmentation in MCF-7 cells (Figure 6).

\section{Role of CSE and crocin on Caspase expression}

To investigate the role of CSE and crocin on caspase's, we analyzed the expression level of caspase 8, caspase 9 and caspase 3 by immunoblot. The western blot analysis of whole cell lysate obtained from MCF-7 cells treated with $10 \mu \mathrm{g} / \mathrm{ml}$ of CSE and crocin revealed an increase

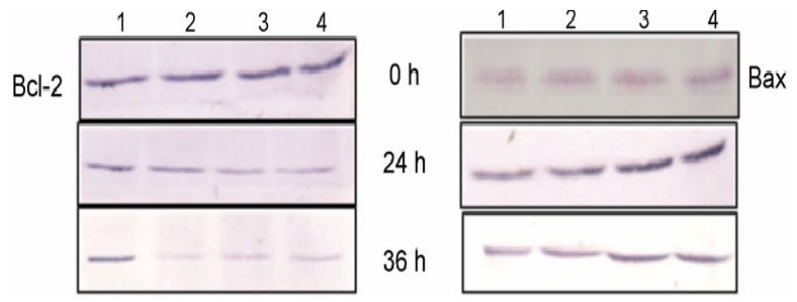

Figure 5. Western Blot Analysis of Bcl-2 and Bax. Western blot analysis of anti-apoptotic protein Bcl-2 and proapoptotic Bax done using whole cell lysate of CSE and crocin treated MCF-7 cells at different time points from 0 to $36 \mathrm{~h}$ : (1) untreated cells used as corresponding controls, (2) etoposide $(50 \mu \mathrm{M})$ treated, (3) CSE (10 $\mu \mathrm{g} / \mathrm{ml})$ treated, and (4) crocin (10 $\mu \mathrm{g} / \mathrm{ml}$ ) treated. Exposure of MCF-7 cells to CSE and crocin resulted in an increase Bax expression and decrease Bcl-2 levels

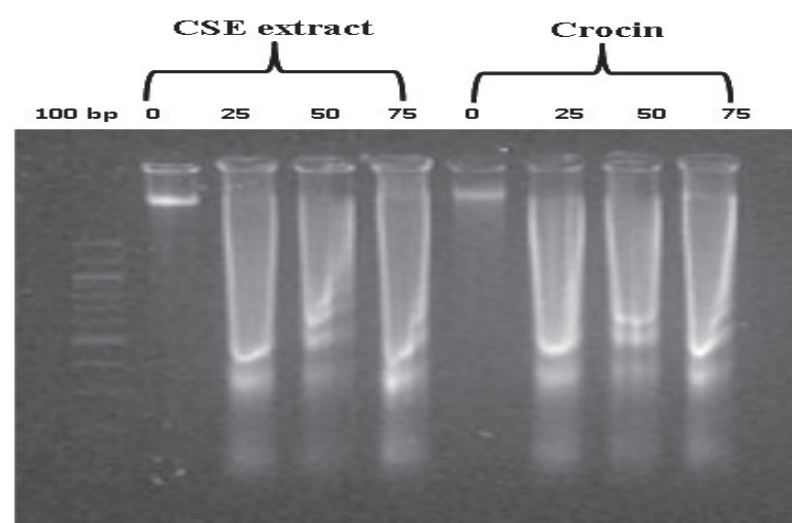

Figure 6. DNA Fragmentation Induced by CSE and Crocin. Agarose gel electrophoresis demonstrating DNA fragmentation in MCF-7 cells: $1 \times 106$ MCF-7 cells treated with $25,50,75 \mu \mathrm{g} / \mathrm{ml}$ of CSE and purified crocin for 24 hours induced classical DNA fragmentation

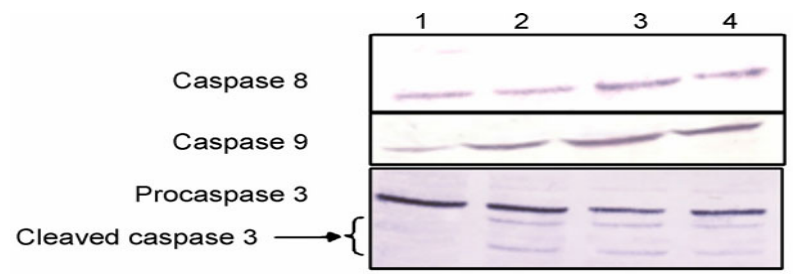

Figure 7. Activation of Caspases $(3,8$, and 9) by CSE and Crocin. Activation of caspase 8, 9, and 3. MCF-7 cells were treated with CSE $(10 \mu \mathrm{g} / \mathrm{ml})$ and Crocin $(10 \mu \mathrm{g} / \mathrm{ml})$ for 24 hours. Whole cell lysate was used for western blot analysis with specific antibodies, respectively: (1) control (untreated MCF-7 cells), (2) etoposide $(50 \mu \mathrm{M})$ treated, (3) CSE (10 $\mu \mathrm{g} / \mathrm{ml})$ treated, and (4) Crocin $(10 \mu \mathrm{g} / \mathrm{ml})$ treated 
Molecular Mechanism of Crocin Induced MCF-7 Cell Death: In Vivo Toxicity Profiling and Ex Vivo Macrophage Activation

in caspase 8 , and 9 expression and there is cleavage of caspase 3 after 24 hours (Figure 7). This data reveals that the apoptosis induction in MCF-7 cells by CSE and crocin mediated by caspase 3 dependent pathway.

\section{Flow cytometry}

To confirm that cell death observed by DNA fragmentation and expression of proapoptotic proteins which corresponds to apoptosis, we analyzed the changes in DNA content by flow cytometry. The profile of PI stained events clearly distinguished nuclei with normal diploid DNA in control cells from the nuclei with hypo diploid DNA found in treated cells. The proportion of cells in the sub-G1 region increased from $3.36 \%$ (control) to $51.45 \%$ (CSE) and $49.85 \%$ (crocin) after 24 hours of treatment (Figure 8). Taken together these results suggest that CSE and crocin were capable of inducing apoptosis in MCF-7 cells with extensive DNA damage.

\section{In vivo pre-clinical toxicity profile}

To determine the maximum In vivo tolerance level of CSE, we treated normal swiss albino mice with CSE $(300 \mathrm{mg} / \mathrm{kg}$ body weight) for 60 days in weekly intervals. In order to analyze the toxicity on normal tissues, we examined the liver, kidney, spleen, lung and heart of treated and untreated groups. Evaluation of numerous histological sections of these tissues from animals treated with CSE did not indicate any detectable pathologic abnormalities as examined by H\&E staining. There were no observable histopathologic differences in these tissues. The liver showed normal hepatic lobular architecture, intact central vein with trapped red blood cells in a liver section from CSE treated animals. The kidney revealed normal glomeruli, proximal and distal tubules, interstitium, and blood vessels (solid arrow heads) (Figure 9A). The splenic follicles and vascular sinosoids were indistinguishable between the CSE treated and untreated control groups. The lung tissue showed normal alveoli (solid arrow heads) (Figure 9B). The heart muscle showed

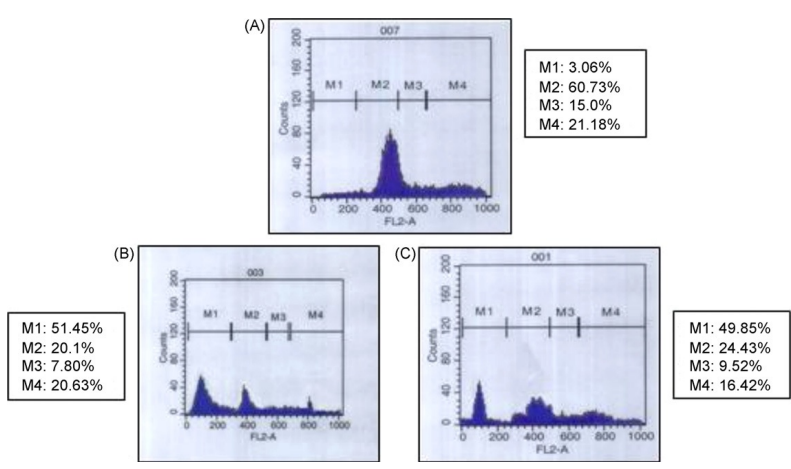

Figure 8. Determination of Sub-G1 DNA Content in MCF-7 Cells by Flow Cytometry. Determination of sub-G1 DNA content in MCF-7 cells by flow cytometry . The $1 \times 10^{6} \mathrm{MCF}-7$ cells were treated with CSE $(10 \mu \mathrm{g} / \mathrm{ml})$ and crocin $(10 \mu \mathrm{g} / \mathrm{ml})$ for 24 hours. Cells were harvested and stained with propidium iodide as described. The area labeled M1 is the sub-G1 apoptotic population, $\mathrm{M} 2$ is $\mathrm{G} 1, \mathrm{M} 3$ is $\mathrm{S}$ and $\mathrm{M} 4$ is $\mathrm{G} 2 / \mathrm{M}$-phase: (A) untreated control cells, (B) MCF-7 cells treated with the CSE (10 $\mu \mathrm{g} / \mathrm{ml})$, and (C) MCF-7 cells treated with Crocin (10 $\mu \mathrm{g} / \mathrm{ml})$. Experiment repeated thrice and the profile was similar

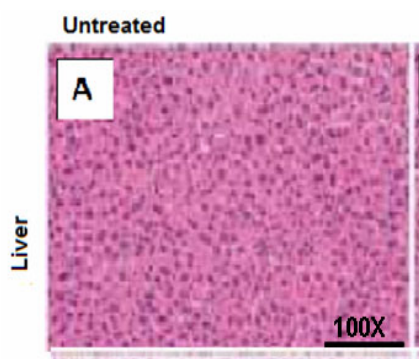

Saffron treated
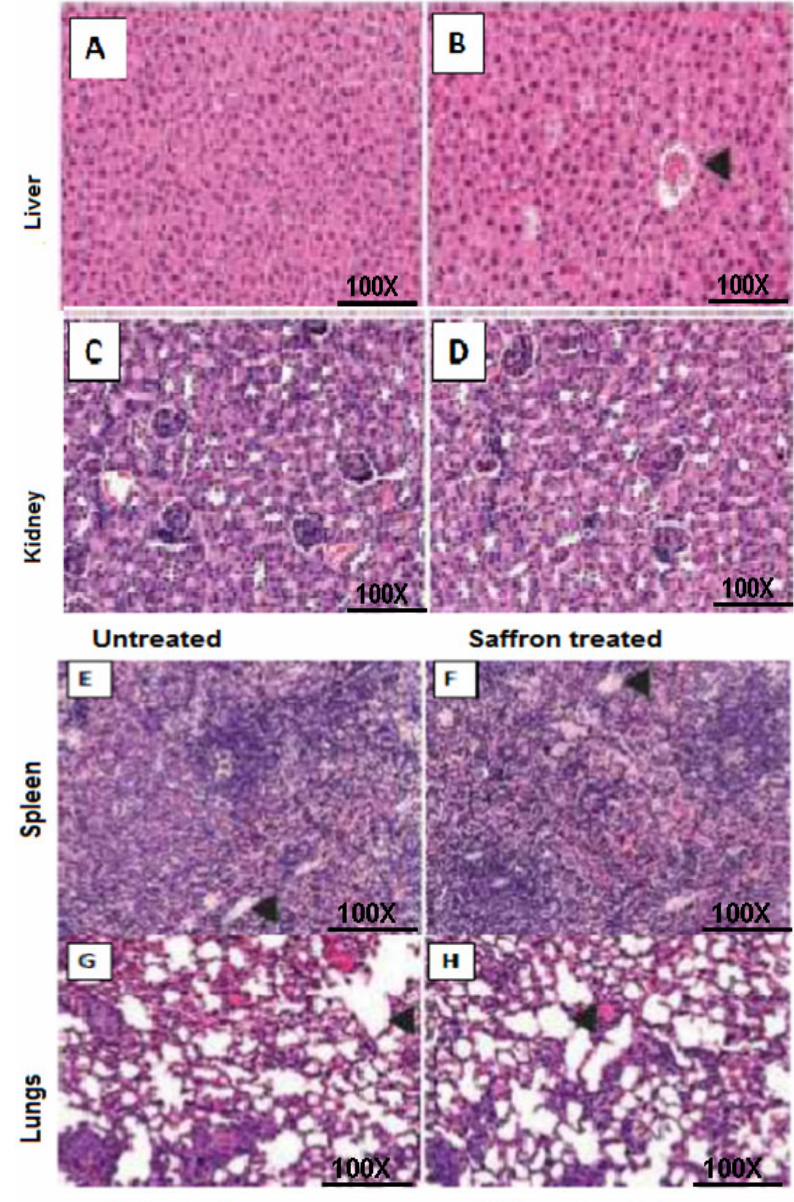

Saffron treated

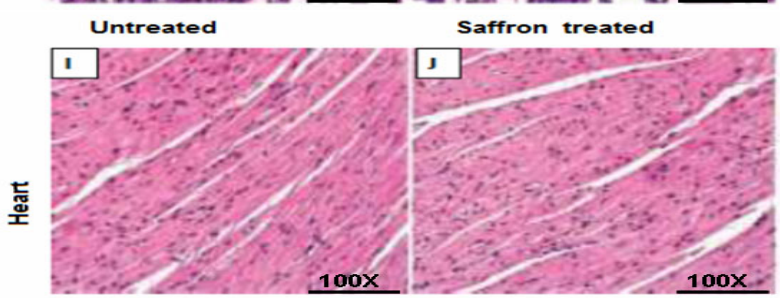

Figure 9. A: Organ Toxicity (Liver and kidney) Profile of CSE treated and untreated Mice. B: Organ Toxicity (spleen and lungs) Profile of CSE treated and untreated Mice. C: Organ Toxicity (Heart) Profile of CSE treated and untreated Mice

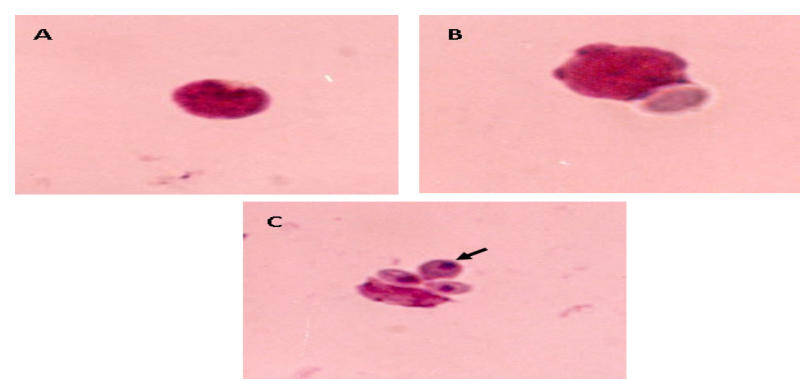

Figure 10. Activation of Peritoneal Macrophage by Crocin. (A) Macrophage (control) (B) Crocin untreated macrophage with yeast $(C)$ Crocin treated macrophage with yeast (arrow head indicates the yeast engulfed by macrophage)

normal morphology among the two groups (Figure 9C).

Ex vivo immune stimulatory effect of purified crocin 


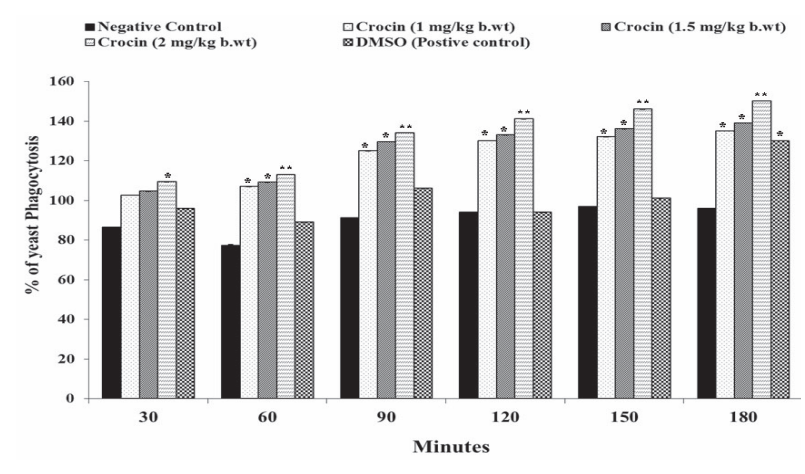

Figure 11. Percentage of Yeast phagocytosis by activated macrophages at different time intervals. Data presented as mean \pm SD of triplicates of three independent experiments. Asterisks indicates the significant difference compare to negative control (*: $\mathbf{P}<0.05, * *: \mathbf{P}<0.001$ )

Peritoneal macrophage were collected from crocin treated mice and observed for phagocytosis after 30 to 180 minutes of incubation with yeast cells. Morphologically, macrophage from crocin treated animals found to be active in time dependent manner and exhibit all the stages of phagocytosis with increasing duration of incubation (Figure 10 and 11).

\section{Discussion}

We and other reported that $C$. Sativus and its major constituent crocin is an effective in vitro anti-proliferative agent of MCF-7 cells (Mousavi et al., 2011; Bakshi et al., 2012; Bizhan Malaekeh-Nikouei et al., 2013; Samarghandian and Borji, 2014). Initiation of apoptosis and proportion of MCF-7 cells attained apoptotic state after treatment with saffron has been well enumerated by flow cytometric analysis (Mousavi et al., 2009; Mousavi et al., 2011). However, the precise role of CSE or crocin on pro-apoptotic, anti-apoptotic, and caspase signaling mediated MCF-7 cell death at molecular level is ambiguous. Bcl-2 family includes key regulators of apoptosis and the molecule is over-expressed in many types of cancer cells (Llambi and Green, 2011). While reduced Bcl-2 expression accompanied with high expression of Bax may promote apoptotic response to anticancer drugs, increased expression of $\mathrm{Bcl}-2$ leads to resistance to chemotherapeutic drugs (Ouyang et al., 2012). In this study, we found that CSE and crocin down regulate the expression of Bcl-2 with simultaneous up regulation of pro apoptotic Bax in MCF-7 cells (Figure 5). Upon receiving death signal in the form of ligands (Fas, Death receptor 3, 4, 5, and TRAIL) or drugs, proapoptotic proteins such as caspase 3,8 and 9 undergo posttranslational modifications that include dephosphorylation and cleavage leading to their activation and formation of death inducing signaling complex and translocated in to mitochondria where apoptosis initiated (ShamasDin et al., 2011). This phenomenon led us to determine consequent signaling cascade of CSE and crocin mediated Bcl-2 down regulation in MCF-7 cells. To address this issue, we determine expression of pro caspase 3, 8 and 9. Treatment of MCF-7 cells with $10 \mu \mathrm{g} / \mathrm{ml}$ of CSE and crocin leads to up regulation of caspase 3, 8 and 9 in time dependent manner (Figure 7). These findings suggest that the CSE and crocin induced apoptosis in MCF-7 cells via the Bcl-2 down regulation and caspase 3 dependent pathways. Biochemical signatures accompanied with apoptosis include chromosomal DNA cleavage into inter-nucleosomal fragments, phosphatidylserine externalization and a number of intracellular substrate cleavages by specific proteolysis (Cohen et al., 1994; Martin and Green, 1995). As apoptosis occurs when DNA damage is irreparable, we tested the efficacy of CSE and crocin on MCF-7 cells DNA fragmentation. Each concentration of CSE and crocin treatment elicits considerable DNA fragmentation after 24 hours (Figure 6). Taken together this data evidenced that CSE and crocin modulating the expression of pro apoptotic markers in MCF-7 cells along with severe DNA damage and thus elicits significant cell death.

Toxicity in many tissues following chemotherapy is a major clinical concern. Therefore, the search for safe, well tolerated regimen has been major goal of clinical cancer research. To determine whether $300 \mathrm{mg} / \mathrm{kg}$ of CSE treatment for 60 days results in toxicities to normal tissues, we examined the liver, kidney, spleen, lung and heart of treated and untreated groups. Evaluation of numerous histological sections of these tissues from animals treated with CSE did not indicate any detectable pathologic abnormalities as examined by H\&E staining. There were no observable histopathologic differences in these tissues.

As a consequence of toxicity, cancer patients are prone for variety of infections due to weakening of their immune system by chemotherapeutic drugs (Vento and Cainelli, 2003). Macrophage playing a pivotal role in neutralizing infections but, deteriorated effect of chemo drugs abrogates its functions in cancer patients. To address this issue and to assess the immune toxicity of crocin, in this study, we tested the efficacy of crocin on macrophage activation (ex vivo). Macrophage collected from crocin treated mice found to be active and its phagocytic ability enhanced in each time intervals of experimental period (Figure 11). Activated macrophages release a wide array of mediators including reactive oxygen and nitrogen species, hydrolytic enzymes, bioactive lipids, and cytokines such as tumor necrosis factor alpha (TNF- $\alpha$ ) (Nathan, 1987; Janeway and Medzhitov, 2002; Martini, 2004). Our ex vivo data reveals that peritoneal macrophage collected from crocin treated mice engulf the yeast prominently however, precise molecular mechanism for macrophage activation by crocin is remains unclear. In support our results, previously Escribano et.al reported that non-toxic dose of saffron derived proteoglycan enhance macrophage mediated nitric oxide (NO) release cum phagocytosis (Escribano et al., 1999). Production of NO is an important cytotoxic function of macrophage to resolve infection of protozoan and bacterial parasites (De Groote and Fang, 1995). Intracellular signaling cascades alter nitric oxide synthase expression in macrophage upon activation and facilitate the release of NO by oxidizing terminal guanidine nitrogen of L-arginine (Raddassi et al., 1994; Dong et al., 1995; Park et al., 1996; Jun et al., 1996). We speculate that in the current study crocin could induce the 
Molecular Mechanism of Crocin Induced MCF-7 Cell Death: In Vivo Toxicity Profiling and Ex Vivo Macrophage Activation

expression of nitric oxide synthase and subsequent NO production in macrophage and thus enhanced phagocytosis of yeast ex vivo.

In conclusion, our study delineates the involvement of pro apoptotic and caspase mediated MCF-7 cell death by CSE and crocin at molecular level accompanied with extensive DNA damage. Further we found that normal swiss albino mice can tolerate the maximum dose of CSE. Crocin enhance macrophage activation and its phagocytic ability ex vivo. However the detailed molecular mechanistic studies are required to translate this formulation in to clinic.

\section{References}

Abdullaev FI (2002). Cancer chemopreventive and tumoricidal properties of saffron (Crocus sativus L.). Exp Biol Med, 227, 20-25.

Abdullaev FI, Espinosa-Aguirre JJ (2004). Biomedical properties of saffron and its potential use in cancer therapy and chemoprevention trials. Cancer Detec Prev, 28, 426-432.

Abe K, Saito H (2000). Effects of saffron extract and its constituent crocin on learning behaviour and long-term potentiation. Phytother Res, 14, 149-52.

Aung HH, Wang CZ, Ni M, et al (2007). Crocin from Crocus sativus possesses significant anti-proliferation effects on human colorectal cancer cells. Exp Oncol, 29, 175-80.

Bakshi H, Touseef T, Fassal G, et al (2012). Crocus sativus L. prevents progression of cell growth and enhances cell toxicity in human breast cancer and lung cancer cell lines. Int J pharma Life Sci, 2, 120-4.

Bakshi H, Sam S, Feroz A, et al (2009). Crocin from Kashmiri saffron (Crocus sativus) induces in vitro and In vivo xenograft growth inhibition of dalton's lymphoma in mice. Asian Pac J Cancer Prev, 10, 887-90.

Bakshi H, Sam S, Rozati R, et al (2010). DNA fragmentation and cell cycle arrest: a hallmark of apoptosis induced by crocin from khashmiri saffron in human pancreatic cancer cell line. Asian Pac J Cancer Prev, 11, 675-9.

Bakshi H, Sam S, Sharma M, et al (2008). Assessment of cytotoxic and apoptogenic activity of Crocus sativus on Human cancer cell lines. Ind J Applied Life Sci, 4, 34-38.

Carol ED, Chun CL, Angela BM, et al (2014). Cancer Treatment and Survivorship Statistics, 2014. CA Cancer J Clin, 64, 252-71.

Chen Y, Zhang H, Tian X, et al (2008). Antioxidant potential of crocins and ethanol extracts of Gardenia jasminoides ELLIS and Crocus sativus L.: a relationship investigation between antioxidant activity and crocin contents. Food Chem, 109, 484-92.

Cohen GM, Sun XM, Fearnhead H, et al (1994). Formation of large molecular weight fragments of DNA is a key committed step of apoptosis in thymocytes. J Immunol, 153, 507-16.

De Groote MA, Fang FC (1995). NO inhibitions: antimicrobial properties of nitric oxide. Clin Infect Dis, 21, 162-5.

Deng Y, Guo ZG, Zeng ZL, et al (2002). Studies on the pharmacological effects of saffron (Crocus sativus L.) - A review. Zhongguo Zhong Yao Za Zhi, 27, 565-8.

Dong X, Yang X, Xie K, et al (1995). Activation of inducible nitric oxide synthase gene in murine macrophages requires protein phosphatase 1 and $2 \mathrm{~A}$ activities. J Leuko Biol, $\mathbf{5 8}$, 725-32.

Escribano J, Diaz-Guerra MJ, Riese HH, et al (1999). In vitro activation of macrophages from corms of Crocus sativus $\mathrm{L}$. Cancer Lett, 144, 107-14.

He SY, Qian ZY, Tang FT, et al (2005). Effect of crocin on experimental atherosclerosis in quails and its mechanisms. Life Sci, 77, 907-21.

Hosseinzadeh H, Ziaee T, Sadeghi A (2008). The effect of saffron, Crocus sativus stigma, extract and its constituents, safranal and crocin on sexual behaviors in normal male rats. Phytomedicine, 15, 491-95.

Janeway CA, Medzhitov R (2002). Innate immune recognition. Ann Rev Immunol, 20, 197-216.

Jorgensen LV, Andersen HJ, Skibsted, LH (1997). Kinetics of reduction of hypervalent iron in myoglobin by crocin in aqueous solution. Free Rad Res, 27, 73-87.

Jun CD, Yoon HJ, Park YC, et al (1996). Synergistic cooperation between thapsigargin and phorbol ester for induction of nitric oxide synthesis in murine peritoneal macrophages. Free Rad Biol Med, 20, 769-76.

Kim T, Jung U, Cho DY, et al (2001). Se-methylselenocysteine induces apoptosis through caspase activation in HL-60 cells. Carcinogenesis, 22, 559-65.

Kumar S, Ikram AB, Adel Al-Ajmi, et al (2011). Changing trends of breast cancer survival in sultanate of oman. J Oncol, 1-7.

Landen JW, Lang R, McMahon SJ, et al (2002). Noscapine alters microtubule dynamics in living cells and inhibits the progression of melanoma. Cancer Res, 64, 4109-14.

Liakopoulou-Kyriakides M, Skubas AI (1990). Characterization of the platelet aggregation inducer and inhibitor isolated from Crocus sativus. Biochem Int, 22, 103-10.

Llambi F, Green DR (2011). Apoptosis and oncogenesis: give and take in the Bcl-2 family. Curr Opin Genet Dev, 21, 12-20.

Lussignoli S, Fraccaroli M, Andrioli G, et al (1999). A microplate based colorimetric assay of the total peroxyl radical trapping capability of human plasma. Anal Biochem, 269, 38-44.

Lv CF, Luo CL, Ji HY, et al (2008). Influence of crocin on gene expression profile of human bladder cancer cell lines T24. Zhongguo Zhong Yao Za Zhi, 33, 1612-7.

Martini FA (2004). Fundamentals of Anatomy and Physiology. $6^{\text {th }}$ ed. New York: Benjamin Cummings, 791-812.

Mousavi S, Afshari JT, Brook A (2008). Study of Cytotoxic Effects of Saffron in MCF-7 Cells. Iranian J Pharm Sci, 4, 261-268.

Mousavi SH, Seyed Adel Moallem, Soghra Mehri, et al (2011). Improvement of cytotoxic and apoptogenic properties of crocin in cancer cell lines by its nanoliposomal form. Pharm Biol, 49, 1039-45.

Mousavi SH, Tavakkol-Afshari J, Brook A, et al (2009a). Direct toxicity of Rose Bengal in MCF-7 cell line: Role of apoptosis. Food Chem Toxicol, 47, 855-859.

Mousavi SH, Tavakkol-Afshari J, Brook A, et al (2009b). Role of caspases and Bax protein in saffron-induced apoptosis in MCF-7 cells. Food Chem Toxicol, 47, 1909-13.

Narayanan K, Balakrishnan A, Miyamoto S (2000). NF-kappaB is essential for induction of pro-inflammatory cytokine genes by filarial parasitic sheath proteins. Mol Immunol, 37, 115-23.

Nathan CF (1987). Secretory products of macrophages. J Clin Invest, 79, 319-26.

Nicoletti I, Migliorati G, Pagliacci MC, et al (1991). A rapid and simple method for measuring thymocyte apoptosis by propidium iodide staining and flow cytometry. J Immunol Meth, 139, 271-9.

Nikouei BM, Mousavi SH, Shahsavand S, et al (2013). Assessment of Cytotoxic Properties of Safranal and Nanoliposomal Safranal in Various Cancer Cell Lines. Phytother Res, 27, 1868-73.

Ouyang L, Shi Z, Zhao S, et al (2012). Programmed cell death pathways in cancer: a review of apoptosis, autophagy and programmed necrosis. Cell Proliferat, 45, 487-98.

Park YC, Jun CD, Kang HS, et al (1996). Role of intracellular 
calcium as a priming signal for the induction of nitric oxide synthesis in murine peritoneal macrophages. Immunol, 87, 296-302.

Pitsikas N, Boultadakis A, Georgiadou G, et al (2008). Effects of the active constituents of Crocus sativus L., crocins, in an animal model of anxiety. Phytomedicine, 15, 1135-9.

Raddassi K, Berthon B, Petit JF, et al (1994). Role of calcium in the activation of mouse peritoneal macrophage: induction of NO synthase by calcium ionophore and thapsigargin. Cell Immunol, 153, 443-55.

Rios JL, Recio MC, Giner RM, et al (1996). An update review of saffron and its active constituents. Phytother Res, 10, 189-93.

Salomi MJ, Nair SC, Panikkar PR (1991). Inhibitory effects of Nigela sativa and saffron (Crocus sativus) on chemical carcinogenesis in mice. Nutr Cancer, 16, 67-72.

Samarghandian S, Borji A (2014). Anticarcinogenic effect of saffron (Crocus sativus L.) and its ingredients. Pharmacognosy Res, 6, 99-107.

Shamas-Din A, Brahmbhatt H, Leber B, et al (2011). BH3-only proteins: orchestrators of apoptosis. Biochim Biophys Acta, 1813, 508-20.

Sheng L, Qian Z, Zheng S, et al (2006). Mechanism of hypolipidemic effect of crocin in rats: crocin inhibits pancreatic lipase. Eur J Pharmacol, 543, 116-22.

Tavakkol-Afshari J, Brook A, Mousavi SH (2008). Study of cytotoxic and apoptogenic properties of saffron extract in human cancer cell lines. Food Chem Toxicol, 46, 3443-7.

Vento S, Cainelli F (2003). Infections in patients with cancer undergoing chemotherapy: aetiology, prevention, and treatment. Lancet Oncol, 4, 595-604. 